\title{
Oxidized LDL Cholesterol Measurement
}

National Cancer Institute

\section{Source}

National Cancer Institute. Oxidized LDL Cholestero/ Measurement. NCI Thesaurus. Code C120635.

The determination of the oxidized LDL cholesterol present in a sample. 